\title{
Daily rhythms in food intake and locomotor activity in a colony of domestic cats
}

\author{
Marine Parker ${ }^{1 *} \mathbb{D}$, Sarah Lamoureux ${ }^{2}$, Etienne Challet ${ }^{1}$, Bertrand Deputte $^{3}$, Vincent Biourge ${ }^{2}$ and Jessica Serra ${ }^{2}$
}

\begin{abstract}
Background: Daily rhythms have been widely investigated in various mammals but, surprisingly, literature is scarce and conflicting regarding the domestic cat, Felis catus. This may come from the difficulty to analyse rhythms in a species showing high interindividual variability and from the common idea that the rhythms of the cat are rather random. To elucidate the subject, two groups of indoor cats (14 in total) living in a cattery room, were followed on a $24 \mathrm{~h} / 7$ day basis, using advanced telemetry technologies, i.e. passive RFID, automated weighing of electronic scales and UWB technology with accuracy ensuring a good reliability of the results.

Results: While covering on average $1.74 \pm 0.4 \mathrm{~km}$ and eating $46.4 \pm 3.6 \mathrm{~g} \mathrm{(} \approx 179 \mathrm{kcal}$ ) of dry food per day, findings indicate $24 \mathrm{~h}$ periodicity in the locomotor and feeding rhythms of the cats. Systematically, their locomotor behaviour was more rhythmic than their eating behaviour $(p<0.01)$, possibly reflecting the flexibility of the eating patterns of the cat initially enabling it to adapt to daily rhythms of its prey. In their daily patterns, the indoor individuals showed two main troughs of activity and food intake -in the middle of the day and in the middle of the night-and two main peaks: one in the morning (especially before sunrise and food renewal), the other in the evening (following the end of the work day of the animal staff and before sunset), supporting previous work demonstrating peaks at dusk and dawn and confirming the crepuscular nature of the species. No general pattern emerged according to a more nocturnal versus diurnal organisation.

Conclusions: Bimodality, more than chronotypes, seems therefore to best characterise the activity and feeding rhythms of the species as it was demonstrated in the individuals among the different categorisations. By validating the use of new tracking technologies as well as of adapted chronobiological parameters to assess the daily rhythm of cats living indoors, this study opens the way for more adequate analyses of cat behaviour through time under various conditions.
\end{abstract}

Keywords: Cat, Circadian rhythms, Feeding pattern, Locomotor activity, Chronobiology

\section{Introduction}

From the short cellular events to long seasonal changes, biological rhythms are systematic for living organisms. They are of importance in the control of daily behaviours. In order to effectively react to the competing demands of life, species adjust their activities (e.g. feeding, sleeping,

\footnotetext{
*Correspondence: marineparker@gmail.com

${ }^{1}$ Institut Des Neurosciences Cellulaires Et Intégratives (INCI), CNRS,

Université de Strasbourg, 8 Allée Du Général Rouvillois, 67000 Strasbourg, France

Full list of author information is available at the end of the article
}

moving) to occur at optimal times [32]. A circadian rhythm displays oscillations of a period of about $24 \mathrm{~h}$. This endogenous cyclicity can for example allow individuals to model their activities on those of their prey or predators, in order to better survive [15]. The circadian rhythms and their consequences can be investigated in various species through different parameters. In mammals, sleep [20], body temperature [28] and also general activity [1] are regulated by an internal master clock located into the suprachiasmatic nucleus of the hypothalamus, which is mainly adjusted by the environmental 
light/dark cycles the individual encounters [3]. In addition, light can directly trigger or inhibit behaviours depending on the species [27].

Literature is scarce and contradictory regarding the rhythmicity of the domestic cat, Felis catus. Hawking et al. [6] reported that cats do not have circadian activity rhythms. Yet, Kuwabara et al. [17] showed circadian fluctuation in total sleep time (slow wave sleep + rapid eye movement sleep) and in brain temperature. They also demonstrated the existence of a bimodal pattern of wakefulness displaying dawn and dusk peaks under artificial light: dark cycle. Randall et al. [25] found a free-running circadian organisation of activity in cats kept in constant darkness as measured by infrared photobeams. These cats, isolated from humans to human noises, showed, in addition, random patterns of activity when kept in constant light. Defining the lifestyle of the cat is indeed difficult: some recorded diurnality in its behaviour $[2,6]$, while others consider it as nocturnal (e.g. [19, 12, 37]) or crepuscular [15]. Yet, this ambiguity may simply be due to the faculty of an individual to show various activity patterns at various times [26] or even result from the adaptability the cat, a predator, must show regarding the variety of the rhythms of its prey in the wild [16]: rodents are usually nocturnal while song birds are diurnal. Besides, a simple diurnal-nocturnal dichotomy is not applicable to all mammals: some species like the degu (Octodon degus), the golden spiny mouse (Acomys russatus), or the tayra (Eira barbara) and grison (Galictis) can shift from diurnal to nocturnal activity patterns under particular environmental conditions [14, 15, 33]. In fact, Horn et al. [7], as well as Piccione et al. [23], observed different chronotypes (behavioural expression of circadian rhythms, here, nocturnality versus diurnality) according to the housing conditions of the cats.

In the wild, the cat is an opportunistic solitary hunter, like many of its fellow felids. It catches numerous small prey per day to sustain its needs as a carnivorous. In accordance with this feature, even when fed by humans, the cat spontaneously eats several small meals per day [18, 8, 21]. Kane et al. [13] reported cats ate approximately 16 (usually 12-20) small meals throughout the 24-h period. Yet, no cyclicity has been reported regarding eating habits in cats so far.

A previous study validated Ultra-WideBands (UWB) technology as a new system to automatically monitor the locomotor behaviour of cats living in group, with more precision than GPS systems and less spatial constraints than passive radio-frequency identification (RFID; [22]). As the study of daily rhythms needs continuous and precise data, we used UWB technology, RFID coupled with automated weighing feeders and specific chronobiological parameters as a new approach to accurately investigate locomotor activity and feeding rhythms in domestic cats living in a cattery.

\section{Materials and methods \\ Animals and conditions}

The tracking technology being installed in a single room, two groups of domestic cats (Felis catus) were observed one after the other in order to maximise our sample size while providing enough living space for each individual to roam in. Each group was studied continuously for 1 week during spring 2015: group A from April 11th to April 18th, group B from May 27th to June 6th. The five females and three males of group A and the two females and four males of group B were all neutered, 5 years old, weighted on average $5.39 \pm 0.33 \mathrm{~kg}$ and belonged to two different breeds: Chartreux and British Shorthair (Table 1). The individuals of both groups had been living together since 2010. Nevertheless, in group A, two individuals (who have been living together since 2010) were introduced at the time of this protocol.

The cats were housed at the cattery of Royal Canin located in the South of France (Aimargues). They lived in a main room of $22.5 \mathrm{~m}^{2}$ [6.4 m (l) $\times 3.51 \mathrm{~m} \mathrm{(w)} \times 2.60 \mathrm{~m}$ (h)] under controlled conditions $\left(20-23{ }^{\circ} \mathrm{C}, 44 \% \mathrm{RH}\right)$. All cats had also free access to an inner courtyard of $7 \mathrm{~m}^{2}$ $[2.9 \mathrm{~m}(\mathrm{l}) \times 2.4 \mathrm{~m}(\mathrm{w}) \times 2.60 \mathrm{~m}(\mathrm{~h})]$, a small confined room opened on fresh external air through narrow gaps underneath and on the top of windows. The cats had at their disposal a wall shelf containing several hiding places and cushions, an "enriched" area containing several cat toys, a wall scratching post, a feeding area, a water bowl, two litter trays, two cat trees with cushions and a plastic seat. Both groups were exposed to the natural light: dark

Table 1 Group, name, sex, breed and mass of each studied cat

\begin{tabular}{lllll}
\hline Group & Name & Sex & Breed & Mass $\mathbf{( k g )}$ \\
\hline A & Fanzine & Female & Chartreux & 3.19 \\
A & Fast & Male & Br. Shorthair & 5.63 \\
A & Favela & Female & Chartreux & 5.01 \\
A & Flora & Female & Chartreux & 4.50 \\
A & Fourrure & Female & Br. Shorthair & 4.15 \\
A & Fredon & Male & Chartreux & 6.66 \\
A & Frimousse & Female & Chartreux & 4.58 \\
A & Frippon & Male & Chartreux & 6.08 \\
B & Fleche & Female & Chartreux & 4.59 \\
B & Flocon & Male & Chartreux & 6.38 \\
B & Fluor & Male & Chartreux & 7.43 \\
B & Fouine & Female & Chartreux & 4.53 \\
B & Franklin & Male & Chartreux & 5.65 \\
B & Freddy & Male & Chartreux & 7.02 \\
\hline
\end{tabular}


cycle, with an average of $13 \mathrm{~h} 39$ of daylight per day for group A and $15 \mathrm{~h} 50$ of daylight per day for group B.

\section{Feeding and human intervention}

All the cats had an ad libitum access to dry food [Fit32 (5.5\% moisture, $32 \%$ protein, $15 \%$ crude fat, $4.6 \%$ crude fibre, $3 \%$ minerals and vitamins, $3859 \mathrm{kcal} / \mathrm{kg}$ ), Royal Canin] and water. The food was renewed every day at 10:00 h. Humans were present within the room around 06:00 $\mathrm{h}$ for cleaning, and then occasionally between 08:30 $\mathrm{h}$ and 12:00 $\mathrm{h}$ and/or between 14:00 $\mathrm{h}$ and 16:00 $\mathrm{h}$ to interact with the cats and check the room.

\section{Locomotor activity, eating behaviour and recording}

Two tags were attached to the collar of each cat, one for locomotor tracking (width $=38 \mathrm{~mm}$, length $=39 \mathrm{~mm}$, height $=16.5 \mathrm{~mm}$; weight $=25 \mathrm{~g}$, approximately $0.5 \%$ of body mass), the second for feeding tracking (width $=15 \mathrm{~mm}$, length $=13 \mathrm{~mm}$, height $=37 \mathrm{~mm}$; weight $=8.2 \mathrm{~g}$, approximately $0.2 \%$ of body mass).

The locomotor tracking tags were Ultra-Wide Band tags (Ubisense, Paris, France), continuously emitting radio waves to antennas placed on strategic spots in the room. This technology automatically records, in real time and three dimensions, the position of a tag-wearing individual all day long with a sampling interval of $0.9 \mathrm{~s}$ and an accuracy of $15 \mathrm{~cm}$ [22]. From these location data, a specific software calculates some behavioural data such as the covered distance of each cat by period of time (periods of $10 \mathrm{~min}$ were used to calculate the rhythm parameters). These tags had no adverse effect on the physical condition of the animals and, with the sensors, use extremely low power radio transmitters and met all applicable EU requirements, including those for human exposure to electromagnetic radiation. Staff entering the room was also equipped with a transmitter attached to a collar to assess the effect of human presence on animal behaviour. This protocol was approved by the ethical committee of Royal Canin. In the results, the mean travelled distance per day refers to the distance travelled by an individual over the collection period, divided by the number of collection days. To infer daily activity patterns, we also calculated the mean travelled distance per cat and per 20 min on a 24-h time period.

Each cat had free access to its own dedicated feeder, thanks to the passive-RFID (M Tronic device, Montévrain, France) tag on its collar which gives access to the food by opening a specific tilting door, access to the other feeders being made impossible. The electronic scales (Metal Process, Montévrain, France) recorded the time and weight of consumptions with a sensitivity of $1 \mathrm{~g}$, and a specific software (M Tronic device, Montévrain, France) was continuously recording the daily consumption for each animal. Files from electronic scales were exported with Excel (Microsoft Office). The raw consumption, i.e. the weight of kibbles ingested (in grammes), and number of meals by period were calculated. In the results, the mean daily consumption per day refers to the total consumption of the individual over the collection period, divided by the number of collection days. After examination of several ingestion kinetics, we considered meals consisted of one or more eating bouts of at least $2 \mathrm{~g}$ separated by an interprandial pause of at least $20 \mathrm{~min}$.

\section{Rhythm parameters and measurements}

To visualise the rhythm of an individual, we used actograms (representing activity rhythms through the covered distance per time) or feedograms (representing feeding rhythms through the food intake per time) representing data for two days per line with successive days appearing on successive lines (Clocklab software, v. 2.72, Actimetrics, Wilmette, IL, USA, associated to Matlab, v. R2013a, MathWorks, Meudon, France). Also, in order to establish whether the cats tended to consume/be active more during night or day hours, we assessed a rate of activity/consumption by hour according to the light condition (night hours vs day hours), using local timing of sunrise and sunsets as phase references.

To measure the period, mode and amplitude, we used the periodograms given by the Clocklab software (v. 2.72, Actimetrics, Wilmette, IL, USA) associated to Matlab (v. R2013a, MathWorks, Meudon, France) which is using the method of Sokolove and Bushell [34]. Periodograms are constructed by the calculation of values for various periods ranging from 5 to of $30 \mathrm{~h}$. Unless the time series contains more than one rhythmic component, the highest peak shown in the periodogram corresponds to the estimated period of the time series. The period (P) of a rhythm is the duration of a full cycle (that is, the reciprocal of its frequency), corresponding to the time interval measured between two episodes that will recur identically during the variation. The highest peak shown in the periodogram graphs yields the period for which the rhythm of the individual repeats its pattern. Typically, the period of a circadian rhythm lasts about $24 \mathrm{~h}$. Secondary peaks can sometimes exist. In most cats, this peak corresponded to 12 -h periods, showing a tendency to bimodality in the rhythms. The amplitude (A) of a rhythm is a relative measure of how much of the activity or food intake is actually rhythmic. The higher amplitude, the more robust the rhythm.

Interdaily stability, intradaily variability and the least active $5 \mathrm{~h}$ period were all determined with the ActiWatch software (v. 7.31, Cambridge NeuroTechnology, Cambridgeshire, UK). The interdaily stability (IS) quantifies 
the variability among successive days, that is, the strength of coupling of the rhythm to stable external zeitgebers $[35,36,38]$. The IS values (arbitrary units), ranging from zero for Gaussian noise to 1 for maximal IS, decrease with higher day-to-day variation of the activity/eating patterns. The intradaily variability (IV) evaluates the fragmentation of the rhythm, that is, the frequency and extent of transitions between rest and activity [35, 36, 38]. The IV values (arbitrary units) vary from near zero for a perfect sine wave to about 2 for Gaussian noise. The least active $5 \mathrm{~h}$ (L5) are computed by averaging the 5 lowest hourly means of the $24 \mathrm{~h}$ pattern $[35,36,38])$. This gives us an indication about the moment daily troughs happen in the pattern of the cats. We can then compare interindividual differences.

\section{Chronotypes}

We based a nocturnal versus diurnal categorisation of the individuals on the position of the least active $5 \mathrm{~h}$ (nocturnal or diurnal), inspection of the actograms (more nocturnal or diurnal activity/consumption peaks) and comparison of the nocturnal/diurnal activity/consumption rates.

\section{Statistical analyses}

Every statistical comparison was made with Sigmaplot (v. 13.0, Systat Inc., San Jose, California, USA). We used unpaired t-tests or Mann-Whitney rank sum tests (when the data passed Shapiro-Wilk test for normality or Brown-Forsythe test for equal variance) to determine the effects of sex (male versus female), group (group A versus group B) or chronotype (nocturnal versus diurnal) on the daily covered distance or food consumption, weight and amplitude, interdaily stability and intradaily variability of the rhythms. Because the data did not follow statistical normality (Shapiro-Wilk test for normality) and could not be normalised with standard transformations, Friedman analyses of variances (ANOVAs) with repeated measures were conducted to compare the covered distance or food consumption according to the hour of the day. Two-way ANOVAs with repeated measures were performed to assess the effects of sex or chronotype on the covered distance and food consumption according to the hour of the day. Tukey post hoc tests with Friedman ANOVAs and Holm-Sidak post hoc tests with twoway ANOVAs were performed. Finally, paired t-tests or Wilcoxon signed rank tests (when the data significantly deviated from normality according to Shapiro-Wilk test) were conducted to evaluate the effect of the variable type (feeding versus locomotor activity) on the chronobiological parameters (i.e. amplitude, interdaily stability and intradaily variability). Our results are given as mean \pm standard error, with a significance threshold of $p<0.05$ (* when $0.01 \leq p<0.05$, ** when $0.001 \leq p<0.01$, **** when $p<0.001$ on bar plots graphs).

\section{Results}

\section{Rhythm of locomotor behaviour}

The daily covered distance of the cats highly varies according to the individual (min: $0.54 \mathrm{~km}$; $\max : 4.13 \mathrm{~km}$ ) and the group: group A covered significantly more daily distance than group B $(3.05 \pm 0.38$ versus $0.77 \pm 0.06 \mathrm{~km}$, respectively; Mann-Whitney, $U=0.0, p<0.001$; Additional file 1). Every cat showed a locomotor rhythm of $24 \pm 0.01 \mathrm{~h}$, with a mean amplitude of $433 \pm 48$ (min: 147; max: 749). The interdaily stability of their locomotor rhythm was of $0.40 \pm 0.03$ (min: 0.16 ; $\max : 0.55$ ) and its intradaily variability of $1.63 \pm 0.09$ ( $\min : 1.18$; max: 2.37 ). We decided to consider an individual displayed a tendency to bimodality when the size of the 12-h peak was superior or equal to half of the 24-h peak. Twelve out of the 14 cats showed this tendency in their activity rhythm, the last 2 being only unimodal (examples in Fig. 1). The least active $5 \mathrm{~h}$ (L5) in the locomotor behaviour of the cats began between 22:00 $\mathrm{h}$ and 01:00 $\mathrm{h}$ for eight cats, between 10:00 $\mathrm{h}$ and 11:00 $\mathrm{h}$ for the six others.

The mean hourly distance covered by the cats differed significantly according to the hour (Fig. 2; Friedman, $\left.\chi_{23}^{2}=146.77, p<0.001\right)$. There were two main peaks of activity during the day: cats were more active in the morning, more precisely between 05:00 $\mathrm{h}$ and 06:00 $\mathrm{h}$ (preceding the sunrise) and between 09:00 $\mathrm{h}$ and 11:00 $\mathrm{h}$ (preceding and during the food renewal), and in the evening, more precisely between 16:00 $\mathrm{h}$ and 18:00 h (following the end of the working period of the caretakers and preceding sunset; Additional file 2). The cats were the least active during two main troughs: between 01:00 h and 03:00 h, and between 12:00 $\mathrm{h}$ and 15:00 $\mathrm{h}$.

\section{Rhythm of eating behaviour}

The cats ate approximately eight meals of $5.9 \pm 0.7 \mathrm{~g}$ a day (Additional file 1), i.e. an average of $46.4 \pm 3.6 \mathrm{~g}$ of dry food per day (min: $27.2 \mathrm{~g}$; max: 72.4 g). No group effect was detected $(50.7 \pm 4.8 \mathrm{~g}$ for group $\mathrm{A}$, $43.1 \pm 5.1 \mathrm{~g}$ for group $\left.\mathrm{B} ; t_{12}=1.045, p=0.316\right)$. Eleven out of the 14 individuals showed a feeding rhythm of $24 \pm 0.04 \mathrm{~h}$, the three others being arrhythmic. The interdaily stability of their feeding rhythm was of $0.30 \pm 0.02$ (min: 0.24; $\max : 0.40$ ) and its intradaily variability of $2.05 \pm 0.06$ (min: 1.59 ; max: 2.27 ). The feeding rhythm mean amplitude of rhythmic individuals was of $253 \pm 23$ (min: 161; max: 390). Seven cats showed a tendency towards bimodality, four others being unimodal and the three others amodal (i.e. arrhythmic). The least active $5 \mathrm{~h}$ (L5) in the eating behaviour of the cats began 


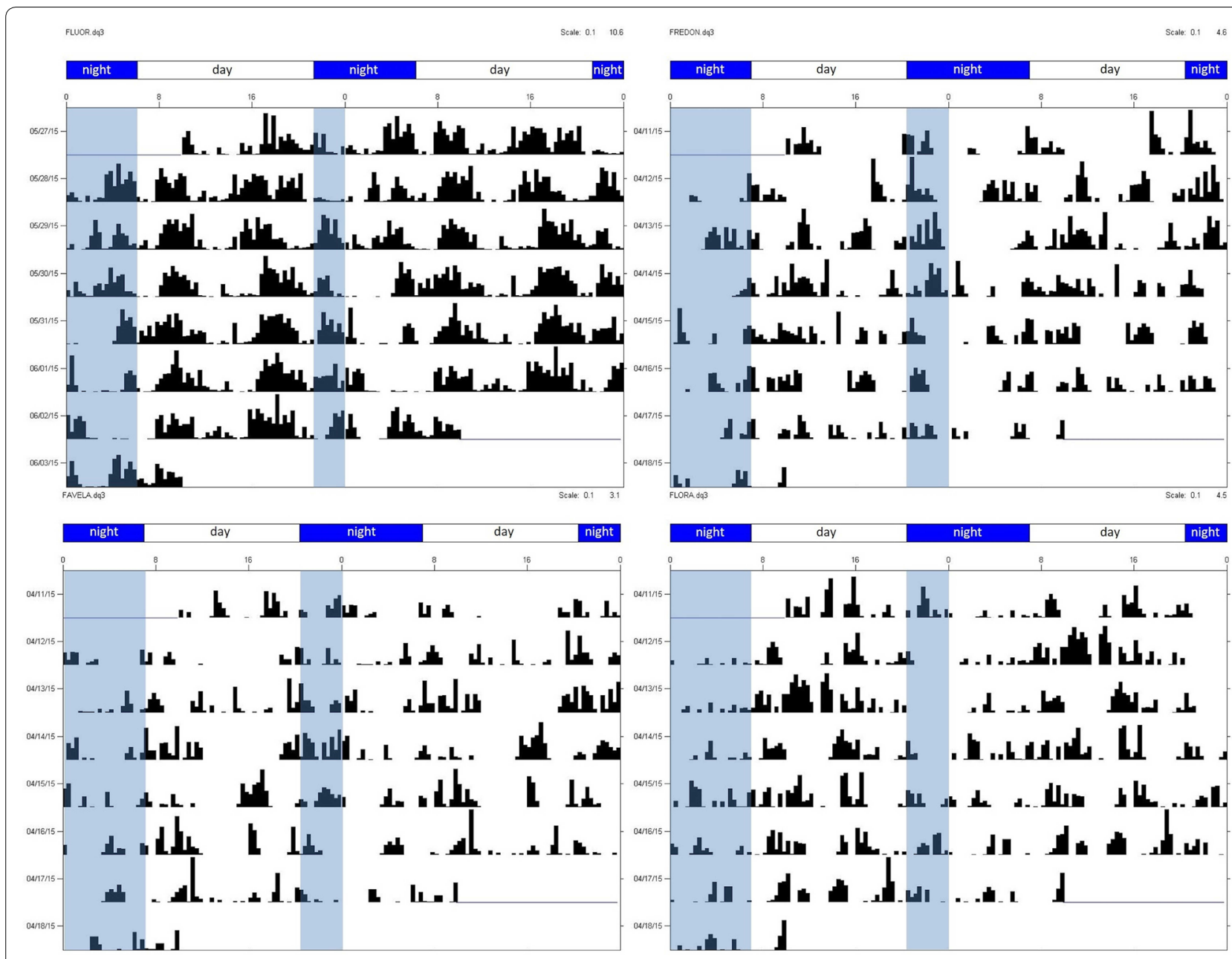

Fig. 1 Actograms of four cats: two bimodal ones (left) and two unimodal ones (right). Actograms show the data (here, activity through the covered distance per time) for 2 days per line, with successive days appearing on successive lines (cf [30]). On the left side of each actogram, blue areas represent night time, white areas day time

between 21:00 $\mathrm{h}$ and 00:00 $\mathrm{h}$ for five cats, between 11:00 $\mathrm{h}$ and 13:00 $\mathrm{h}$ for the nine others.

The mean hourly food intake of the cats differed significantly according to the hour (Fig. 2, Friedman, $\left.\chi_{23}^{2}=112.18 ; p<0.001\right)$. There were two mains peaks of consumption during the day: they ate more between 04:00 $\mathrm{h}$ and 10:00 $\mathrm{h}$ (mostly preceding the sunrise and food renewal), and between 17:00 $\mathrm{h}$ and 21:00 h (following the end of the work of the caretakers and preceding sunset; Additional file 3). The cats ate less during two main troughs: between 01:00 $\mathrm{h}$ and 02:00 $\mathrm{h}$ and between 12:00 $\mathrm{h}$ and 15:00 $\mathrm{h}$.

\section{Influence of sex}

The males were significantly heavier and tended to cover more distance daily than the females (Table 2). When looking at the division in 20-min increments, the males covered significantly more distance than the females at several occasions during the day (top of Fig. 3) The activity rhythm (AR) of the males tended to be higher in amplitude and more interdaily stable than that of the females (Table 2). However, there was no significant difference concerning the intradaily variability (IV) of their AR.

On a daily basis, the males ate significantly more food than the females (Table 2). The amplitude of the feeding rhythm (FR) of the rhythmic cats, interdaily stability and intradaily variability of every cat did not significantly differ according to their sex. Nevertheless, it is worth noting that all the three arrhythmic cats in their eating behaviour (not taken into account when comparing the FR amplitude) were females. The males ate significantly more food than the females in late night and late afternoon (top of Fig. 4; Two-way RM ANOVA, interaction: $F_{71,852}=1.590$, $p<0.01$ ) whereas the females ate significantly more food 

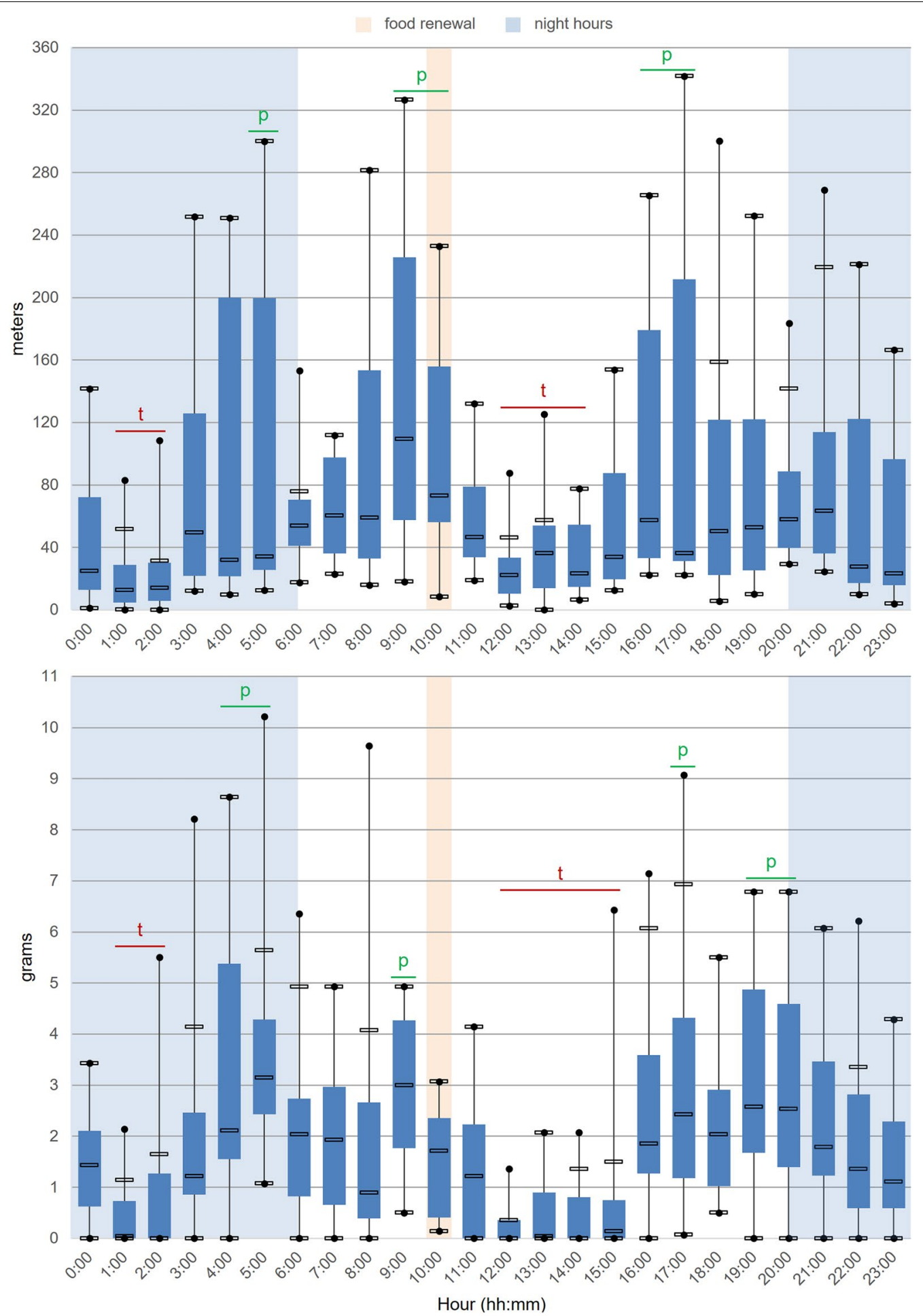

Fig. 2 Mean daily covered distance (metres, top) and food consumption (grammes, bottom) of the cats $(n=14)$ every hour. Box plots represent first (Q1), second (median) and third quartile (Q3), minimum, and maximum of the data, as well as the smallest data superior to the low frontier $(\mathrm{LF}=\mathrm{Q} 1-1,5 \times(\mathrm{Q} 3-\mathrm{Q} 1))$ and the highest data inferior to the high frontier $\left(\mathrm{HF}=\mathrm{Q} 3+1,5^{*}(\mathrm{Q} 3-\mathrm{Q} 1)\right)$. $(p)$ indicates a significant peak, $(t)$ indicates a significant trough 
Table 2 Results of locomotor activity and feeding behaviours and rhythms of the cats according to their sex (male versus female)

\begin{tabular}{|c|c|c|c|c|c|}
\hline & Male $(n=7)$ & Female $(n=7)$ & Test & Test value & Significance \\
\hline Mass (kg) & $6.41 \pm 0.26$ & $4.36 \pm 0.22$ & t-test & $t_{12}=-6.071$ & $p<0.001$ \\
\hline $\mathrm{DCD}(\mathrm{km})$ & $2.40 \pm 0.57$ & $1.09 \pm 0.26$ & Mann-Whitney & $U=10.0$ & $p=0.073$ \\
\hline AR amplitude & $533 \pm 70$ & $332 \pm 39$ & Mann-Whitney & $U=10.0$ & $p=0.073$ \\
\hline ARIS & $0.45 \pm 0.03$ & $0.35 \pm 0.04$ & t-test & $t_{12}=-1.971$ & $p=0.072$ \\
\hline AR IV & $1.60 \pm 0.15$ & $1.66 \pm 0.10$ & t-test & $t_{12}=0.325$ & $p=0.751$ \\
\hline $\mathrm{DFI}(\mathrm{g})$ & $52.6 \pm 3.5$ & $40.2 \pm 5.6$ & Mann-Whitney & $U=7.0$ & $p<0.05$ \\
\hline FR amplitude & $267 \pm 28$ & $230 \pm 40$ & t-test & $t_{9}=-0.758$ & $p=0.468$ \\
\hline FR IS & $0.33 \pm 0.02$ & $0.27 \pm 0.03$ & t-test & $t_{12}=-1.546$ & $p=0.148$ \\
\hline FR IV & $1.97 \pm 0.08$ & $2.14 \pm 0.13$ & t-test & $t_{12}=1.444$ & $p=0.174$ \\
\hline
\end{tabular}

$D C D$ daily covered distance, $A R$ activity rhythm, IS interdaily stability, $I V$ intradaily variability, $D F I$ daily food intake, $F R$ feeding rhythm

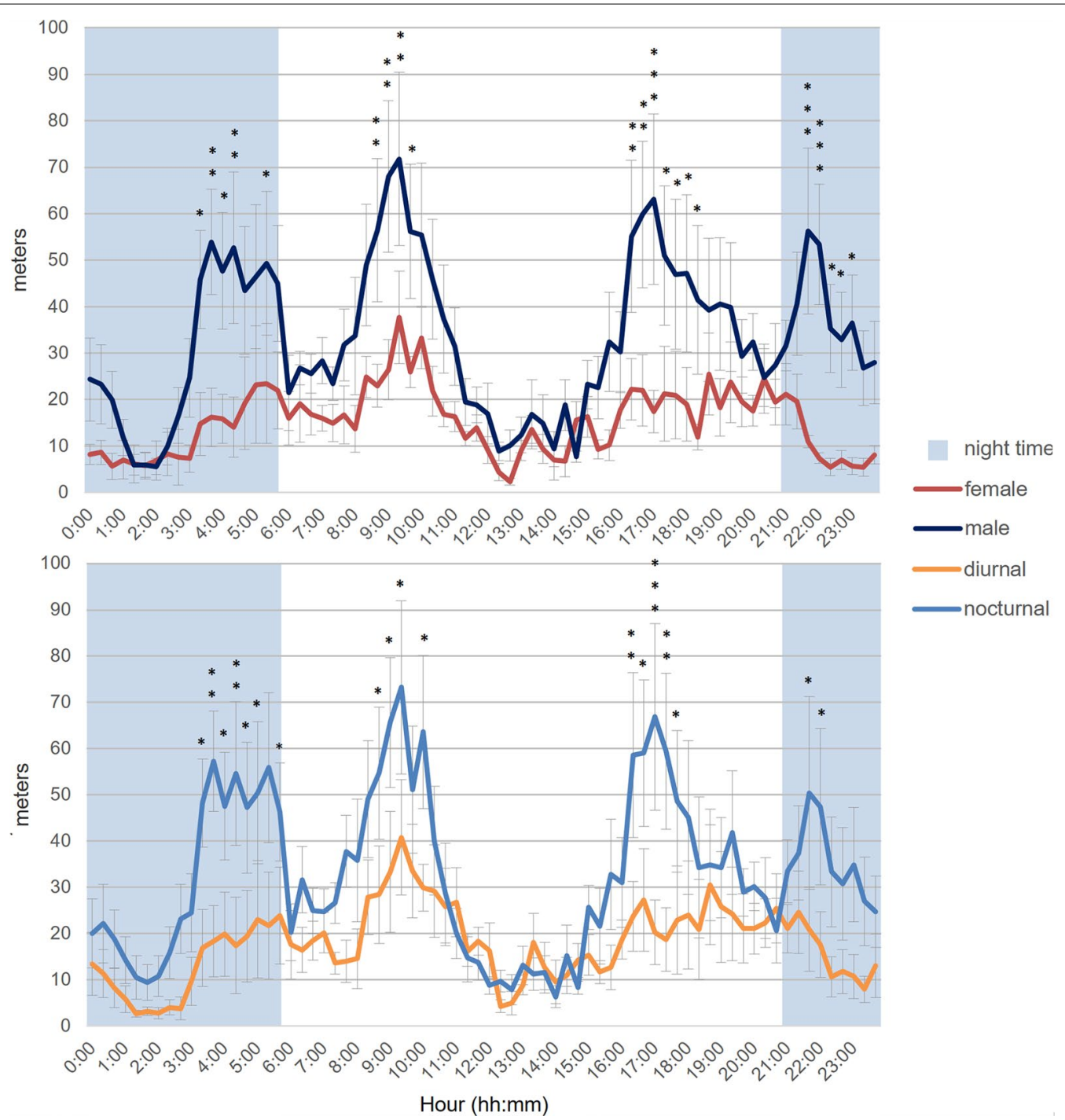

Fig. 3 Mean daily distance (metres) covered every 20 min according to the sex (top) and chronotype (bottom). Female $(n=7)$ vs male ( $n=7)$ and diurnal $(n=8)$ vs nocturnal $(n=6)$. Error bars represent standard errors, ${ }^{*}$ indicates $p<0.05$, ${ }^{* *}$ indicates $p<0.01,{ }^{* * *}$ indicates $p<0.001$ 
than the males only at 20:20 (Holm-Sidak post hoc test, $p<0.01)$.

\section{Chronotype}

Six females out of seven were categorised as globally diurnal, while five males out of seven were categorised as globally nocturnal (see examples in Fig. 5).

No statistical difference occurred between the chronotypes concerning the daily covered distance (Table 3 ). The activity rhythm (AR) of the nocturnal categorised individuals was significantly higher in amplitude and more interdaily stable than that of the diurnal categorised ones (Fig. 6). No significant difference stood out concerning the intradaily variability (IV) of the AR according to the chronotype (Table 3). The nocturnal individuals covered significantly more distance than the diurnal individuals most of the times (Two-way RM ANOVA, interaction: $F_{71,852}=2.274, p<0.001$ ), except during daily troughs around midnight and midday (bottom of Fig. 3).

No statistical difference was detected between the daily consumption, amplitude, interdaily stability or intradaily variability of the feeding rhythm (FR) of the nocturnal categorised individuals compared to the diurnal categorised ones (Table 3). Albeit, the nocturnal categorised individuals tended to eat with a more interdaily stable rhythm than the diurnal categorised ones. It is relevant to note that the only three arrhythmic cats in their eating behaviour (not taken into account when comparing

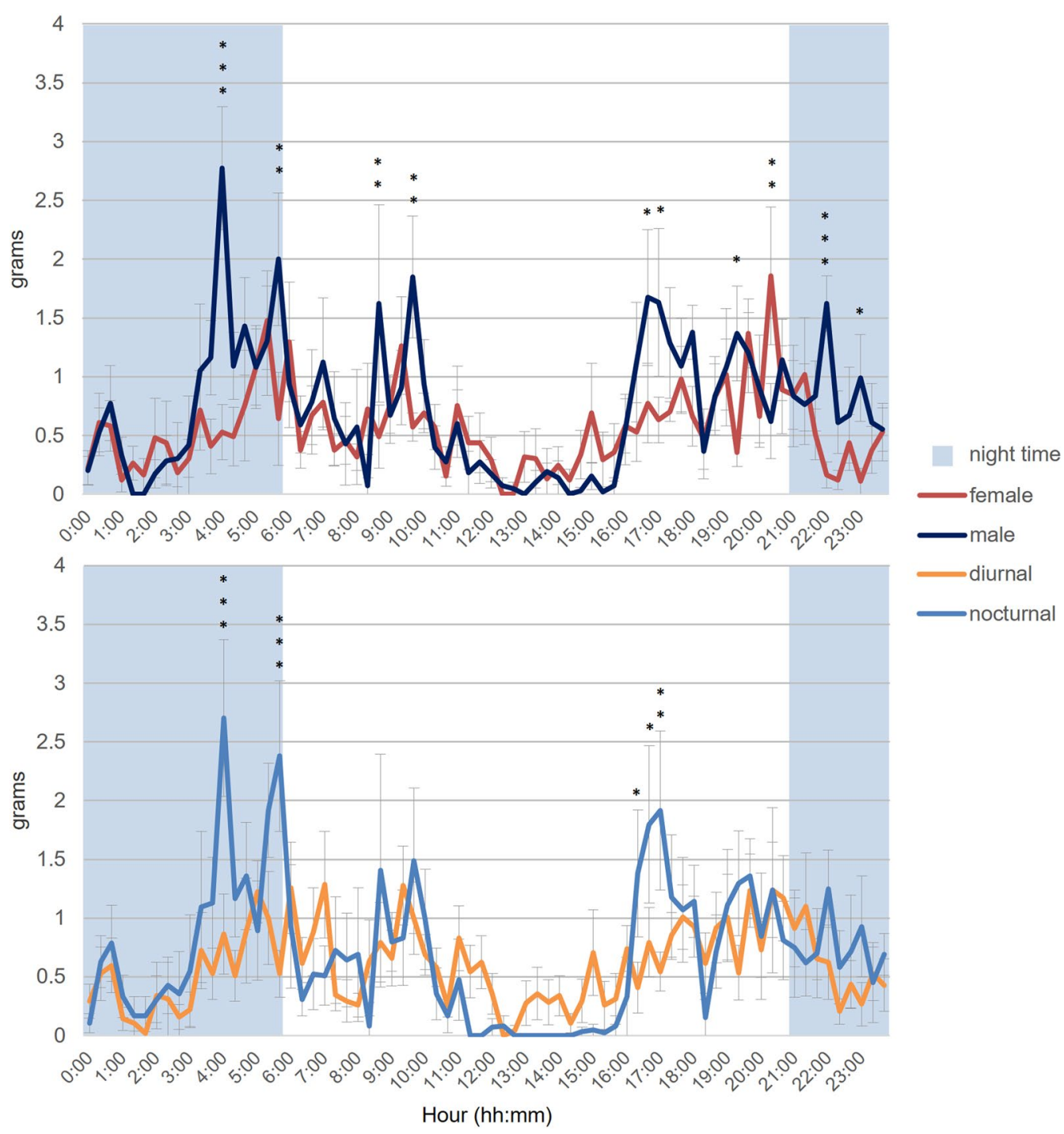

Fig. 4 Mean daily food consumption (grammes) every 20 min according to the sex (top) and chronotype (bottom). Female $(n=7)$ vs male $(n=7)$ and diurnal $(n=8)$ vs nocturnal $(n=6)$. Error bars represent standard errors, ${ }^{*}$ indicates $p<0.05$, ** indicates $p<0.01,{ }^{* * *}$ indicates $p<0.001$ 


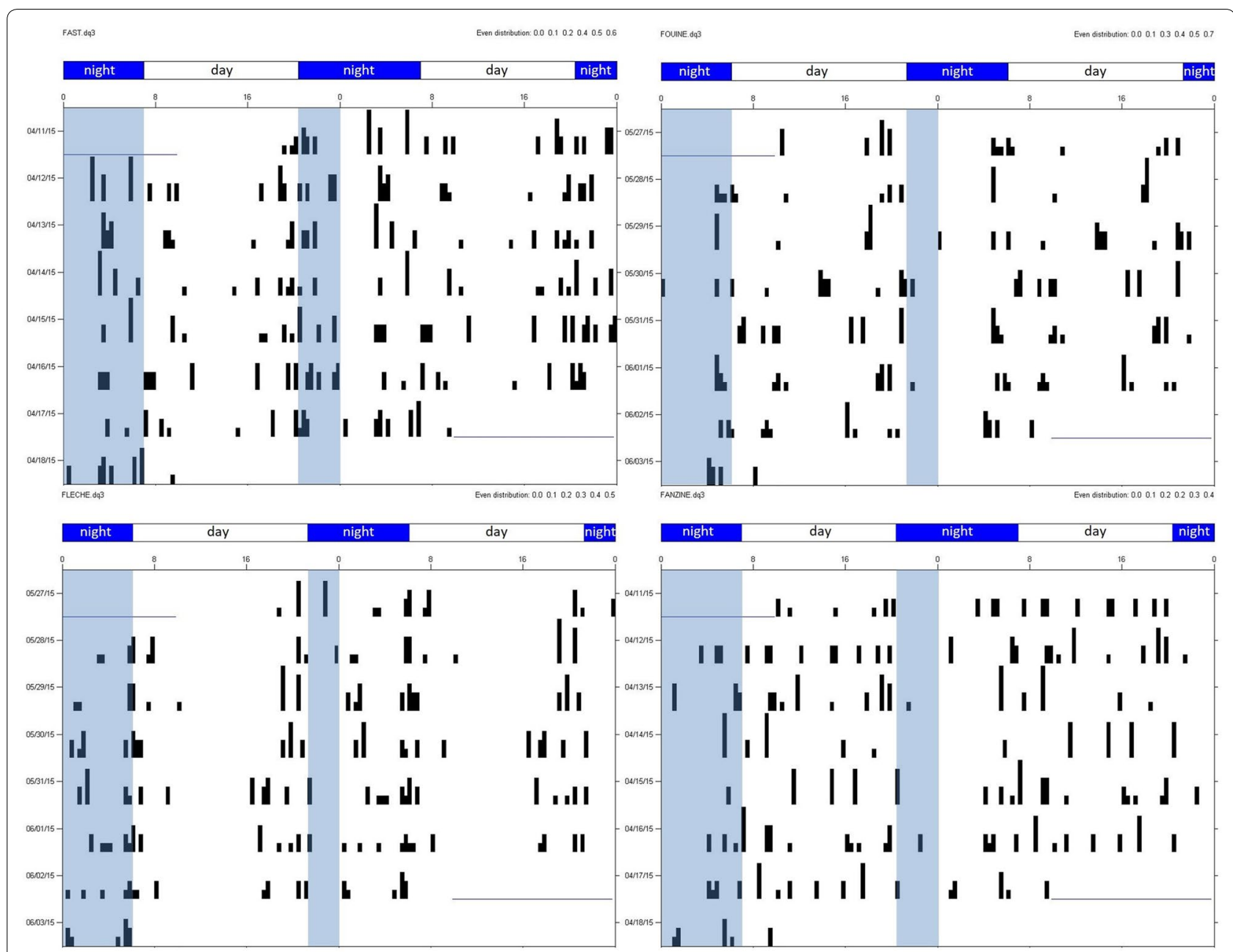

Fig. 5 Feedograms of two nocturnal categorised individuals (left) and two diurnal categorised individuals (right). Actograms (or, here, feedograms) show the data (here, feeding behaviour through the food intake per time) for 2 days per line, with successive days appearing on successive lines (cf [30]). On the left side of each actogram, blue areas represent night time, white areas day time

Table 3 Results of locomotor activity and feeding behaviours and rhythms of the cats according to their chronotype (diurnal versus nocturnal)

\begin{tabular}{|c|c|c|c|c|c|}
\hline & Diurnal $(n=8)$ & Nocturnal $(n=6)$ & Test & Test value & Significance \\
\hline $\mathrm{DCD}(\mathrm{km})$ & $1.28 \pm 0.45$ & $2.37 \pm 0.49$ & t-test & $t_{12}=1.635$ & $p=0.128$ \\
\hline AR amplitude & $328 \pm 32$ & $572 \pm 67$ & t-test & $t_{12}=3.448$ & $p<0.01$ \\
\hline ARIS & $0.34 \pm 0.03$ & $0.48 \pm 0.02$ & t-test & $t_{12}=3.489$ & $p<0.01$ \\
\hline ARIV & $1.74 \pm 0.13$ & $1.48 \pm 0.09$ & t-test & $t_{12}=-1.553$ & $p=0.146$ \\
\hline DFI (g) & $43 \pm 6$ & $51 \pm 4$ & t-test & $t_{12}=1.064$ & $p=0.308$ \\
\hline FR amplitude & $226 \pm 48$ & $276 \pm 19$ & Mann-Whitney & $U=7.00$ & $p=0.177$ \\
\hline FRIS & $0.27 \pm 0.02$ & $0.34 \pm 0.02$ & t-test & $t_{12}=2.088$ & $p=0.059$ \\
\hline FR IV & $2.10 \pm 0.15$ & $1.99 \pm 0.06$ & t-test & $t_{12}=-0.853$ & $p=0.410$ \\
\hline
\end{tabular}

$D C D$ daily covered distance, $A R$ activity rhythm, IS interdaily stability, $I V$ intradaily variability, $D F /$ daily food intake, $F R$ feeding rhythm 

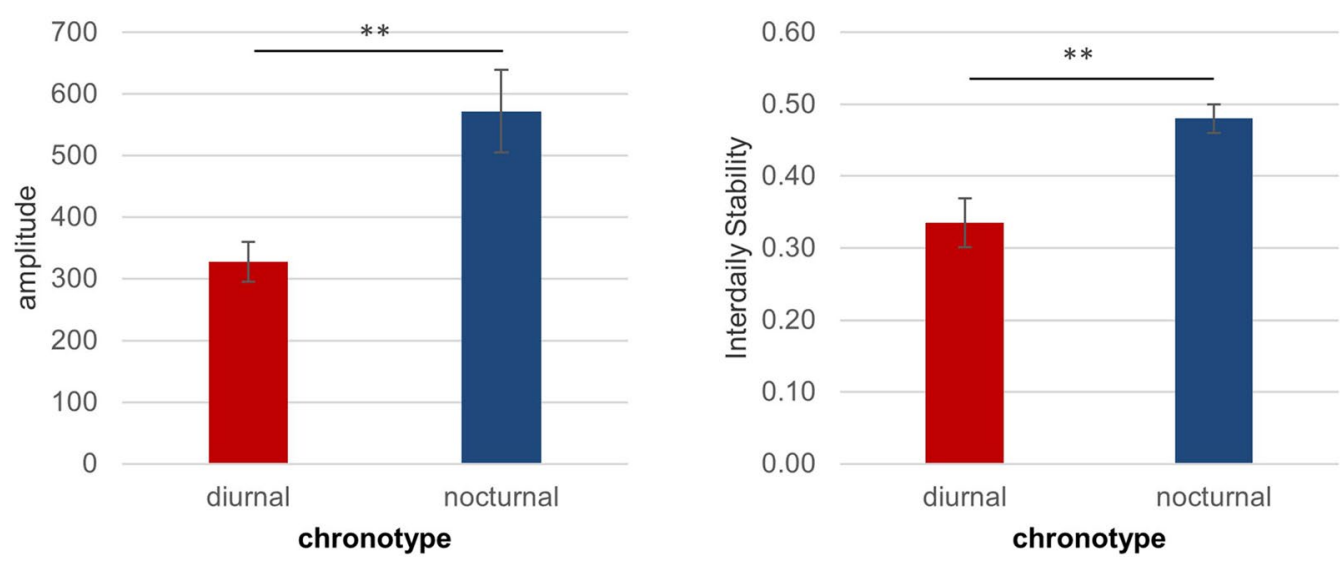

Fig. 6 Mean activity rhythm amplitude (left) and interdaily stability (right) according to the chronotype. Diurnal $(n=8)$ versus nocturnal $(n=6)$. Error bars represent standard errors, ${ }^{* *}$ indicates $p<0.01$

the FR amplitude) were categorised as globally diurnal (diurnal rhythmic activity rhythm). When looking at the consumption every $20 \mathrm{~min}$, the nocturnal categorised individuals ate significantly more food than the diurnal categorised ones (Two-way RM ANOVA, interaction: $F_{71}$, ${ }_{852}=1.458, p<0.05$ ) at several times (bottom of Fig. 4).

\section{Locomotor versus feeding rhythms}

The amplitude and interdaily stability (IS) of the locomotor rhythm (LR) were significantly higher than those of the feeding rhythm (FR) (Amplitude: $463 \pm 57$ versus $253 \pm 23$, respectively; paired t-test, $t_{10}=3.872, p<0.01$; IS: $0.40 \pm 0.03$ versus $0.30 \pm 0.02$, respectively, paired $\mathrm{t}$-test, $t_{13}=3.096, p<0.01$ ). The intradaily variability (IV) of the locomotor rhythm was significantly lower than the IV of the feeding rhythm $(1.63 \pm 0.09$ versus $2.05 \pm 0.06$, respectively; Wilcoxon, $Z=2.542, p<0.01$ ).

\section{Discussion}

Our initial article described the usefulness of UltraWideBands (UWB) set-up to study the individual activity and spatial organisation of 6 free-living indoor cats [22]. In another but larger group of indoor cats $(n=14)$, the present study provides the first set-up combining UWB to record the amount of locomotor activity and passive RFID tags coupled with automated feeder to record eating behaviour. A chronobiological analysis of the continuously recorded data $24 \mathrm{~h} / 24$ over seven days allowed us to assess daily rhythmicity of locomotor activity and eating pattern in a colony of domestic cats living collectively and having ad libitum access to dry food and water.

The rest-activity rhythm is commonly studied using actigraphy, a non-invasive measure of circadian activity. The parameters that described rhythm characteristics included amplitude (A), period ( $\mathrm{P}$ ) and phase. Other analyses, such as interdaily stability (IS), intradaily variability (IV) and the least active $5 \mathrm{~h}$ (L5), had first been developed by Witting et al. [38] in order to study the effect of age and Alzheimer's disease on rest-activity rhythm. These variables, called nonparametric as they are not associated with parameters of a known function, were later used by Van Someren et al. $[35,36]$ who described them as a more appropriate way to investigate and discriminate disturbed circadian rhythms, as well as sensitive to change even in small samples [36]. The rhythms of the cat having previously been described as variable or irregular, these analyses seemed more fitted for our study. Besides, Piccione et al. [23] already used them to study the influence of different housing conditions on daily activity rhythm in cats.

Using precise and elaborate animal tracking methods, we mainly observed bimodality in the activity and feeding rhythms of these indoor cats with crepuscular peaks. Their bimodal patterns were not affected by sex or chronotypes. Hawking et al. [6] described many short bursts of activity distributed irregularly throughout the 24-h period, with no evidence of a daily cycle in a laboratory isolated cat. On the same year, Kavanau [15] agreed in classifying the activity of the cat as arrhythmic. Nevertheless, the very small sample size in both studies $(n=1)$ makes this conclusion doubtful. Recording the behaviour of more numerous individuals, we have demonstrated 24-h periodicity of locomotor and eating behaviour in every cat or almost every cat (11 out of 14), respectively.

The least active $5 \mathrm{~h}$ (L5), previously used only once on the activity rhythms in cats [23], have proved to be a pertinent rhythmic parameter (i.e. phase-marker) to compare in our study. They indeed corresponded to the main daily trough: the hours of the day when the cats 
were significantly moving and eating less coincided with the locomotor activity and eating L5, occurring either in the middle of the night, or in the middle of the day. The nocturnal decrease of activity in eight out of the 14 cats reminds the results of Hawking et al. [6] who noted the total duration of activity of a laboratory cat during light was about 1.4 times that of the activity during night during a $12 \mathrm{~h}$ light-dark cycle.

Besides, the rhythmic behaviours of eating and locomotor activity of the cats were notably impacted by twilight, as already observed in the literature $[2,5,9,11,15$, $17,24]$. The many authors who reported peaks of activity at dawn and dusk sometimes characterised these specific moments as key periods in biological and ecological processes as prey activity, food condition, body temperature, or colonic motility $[4,9,11,16,26]$. In our colony, when looking at the daily activity and eating graphs according to the hour of the day, consumption and activity peaks were indeed noted mainly preceding sunrise (between 04:00 $\mathrm{h}$ and 06:00 $\mathrm{h}$ ) and sunset (between 16:00 $\mathrm{h}$ and 21:00 h), especially in the most active group (B). Positive modulators of these peaks also relied on anticipation of food renewal in the morning and end of human presence in the late afternoon. Yet, if the cats showed ultradian rhythms with period of $6 \mathrm{~h}$ or less rather than bimodal 24-h rhythms, peaks in the periodograms would then rise around $6 \mathrm{~h}$ or at lower periods. This was not the case, i.e. based on periodograms, the cats showed only significant peaks at $24 \mathrm{~h}$ and shorter ones at $12 \mathrm{~h}$. Therefore, we conclude of two main daily peaks of locomotor activity and food consumption, corresponding mostly to anticipation of twilights (i.e. sunrise and sunset).

A great interindividual variability was observed in the eating and activity behaviour of this population, as regularly found in the literature (e.g. [21, 10, 26, 31]). The sex of the cats was a factor that significantly impacted their behaviour. The males, heavier than the females, tended to be more active and were more rhythmic in their locomotor behaviour as shown by a trend for larger daily amplitude and lower interdaily stability. They ate significantly more than the females and none of them were arrhythmic in their eating behaviour, contrary to three females out of seven. When looking at the mean hourly covered distance and consumption, we noticed that the sex differences only happened at the peak hours, while both males and females diminished their activity and consumption simultaneously in the middle of the day and middle of the night.

Circadian rhythmicity can only be measured in constant conditions of light or darkness. Such study conditions enable the detection of endogenous behaviour but can erase external factors determining the natural patterns in animals by not matching natural environmental conditions. Here, we measured daily rhythmicity in indoor rooms where ambient humidity and temperature were kept constant, but natural daylight was received through several bay windows. Although this environment prevented us to generalise our results to cats living in outdoor conditions, it highlighted the impact of daylight fluctuations, separated from other environmental daily variations such as in ambient temperature and humidity, on the locomotor and feeding rhythms of the cats we studied. Moreover, the similarities we observed between the behaviour of the cats of these studies compared to cats living in wilder conditions, such as bimodality and crepuscularity in their rhythms $[4,7]$ demonstrate some factors determining their natural behaviour were still present in the indoor environment they lived in for the present study.

Based on actogram characteristics, L5 values, and nocturnal and diurnal activity/consumption rates, we attempted to further investigate differences among individuals by categorising them according to typical dominant chronotypes: diurnal versus nocturnal. The main difference between diurnal categorised individuals and nocturnal categorised individuals resides in the more pronounced peaks of activity and consumption at twilights in the nocturnal categorised ones, while the activity and consumption troughs are similar between the two types of individuals. Therefore, the chronotype categorisation, which has been commonly used in other species, is difficult to highlight in the cats, which echoes the variable and contradictory categorisations in the literature (e.g. [12, 19, 37]). Refinetti et al. [31] noticed the chronotype spread (i.e. a measure of the variability of chronotypes among individuals) was the greatest in cats $(23 \mathrm{~h})$ compared to 15 other species, concluding the diurnal-nocturnal dichotomy should not apply to cats, as some individuals are mostly active at day while others are mostly active at night. Furthermore, for Refinetti [29], an absence of daily rhythm in the body temperature of the cat as found in the study of Hawking et al. [6] indicates how the cat distinguishes itself from pure nocturnal species or diurnal species for which the body temperature reaches its acrophase, respectively, during the night or during the day.

No general pattern emerged according to the chronotype categorisation. Nevertheless, regular peaks in the feeding rhythm, and mostly in the activity rhythm of the cats, have decidedly been demonstrated in every cat, along a 24-hours periodicity. More precisely, most cats showed two main peaks and troughs in the day, different from unimodal circadian rhythms where only one main peak and one main trough are usually demonstrated. Bimodality, more than chronotypes, seems therefore the best way to categorise the activity and feeding rhythms 
of the cats. Accordingly, Randall et al. [26] suggested that "two peaks may be the one factor that is common to the idiosyncratic patterns of entrainment in this species" and Refinetti et al. [31] detected bimodality in the activity rhythm of cats while chronotypes varied greatly among individuals.

It is worth noting that some individuals-the nocturnal categorised ones-ate practically not at all in the middle of the day (between 11:20 and 15:00 h). This highly pronounced trough, studied on a 7 days collection period, should constitute a pertinent feature for the eating behaviour of this species.

Systematically, the locomotor behaviour of the cats was more rhythmic than their eating behaviour: the activity rhythm of the cats was proved to have higher rhythm amplitude, interdaily stability, less intradaily variability, and every cat showed a 24-h periodicity in their activity rhythm, while three cats were arrhythmic in their eating behaviour. This difference in rhythmicity may explain the less pronounced differences between categories in the feeding rhythm of the cats, than in the locomotor activity rhythm. Besides, this observation may be due to the opportunistic nature of this solitary hunter which, in the wild, feeds on several small prey per day with various rhythms (notably, diurnal birds and nocturnal rodents) and may therefore display flexibility in its eating patterns to adapt to the daily rhythms of its prey, as suggested by Konecny [16].

One difficulty in the analyses of this study relied in group differences. The mean daily covered distance differed significantly between them, group B being more active. This may be explained by the fact that individuals of group B had been living together for 5 years, whereas two cats of group A were new to the group. Difference in activity rate might be due to avoidance, a common aspect in a solitary species in spite of large inter individual variation in tolerance: less tolerant individuals spending more time in avoiding other conspecifics.

Along with this difference in covered distance, a group effect affected sex and chronotype ratios: most cats of group B were males, most individuals of group A were females and males and females were mainly classified as nocturnal and diurnal, respectively. Therefore, we could not cross the sex and chronotype effects since it was not equally distributed, and could not distinguish the sex effect, the group effect and the chronotype effect from each other. Mainly, the males, nocturnal and from group $B$ were more rhythmic and active than the females, diurnal and from group A. Nevertheless, this group difference is interesting as it underlines the plastic behavioural characteristic of this species, able to accommodate to group behaviours [23]. Furthermore, it would be interesting to establish whether intra-individual plasticity is stable or more variable with longer durations of data collection. It is noteworthy that cats of a same group showed very similar rhythms, while cats between the groups were more different. This social aspect of the species living collectively may confer an evolutionary advantage as it allows the individuals to adapt to various living conditions.

Variations in activity and food intake may be sensitive to exogenous factors, such as temperature or photoperiod, and to human intervention. In our conditions, we could not standardise human activity due to time constraints imposed to technicians. This might have differentially affected the activity of the cats. A greater sample size and a standardisation of human activity might help in search of a daily rhythmicity in the activity of the domestic cat.

Moreover, it would be of certain interest to compare the rhythmic behaviours of indoor cats, such as those of this study, with the behaviours of individuals having access to outdoor environment. Differences in housing conditions were proven to result in distinct daily activity rhythms: a group of pet cats having low access to an outdoor garden lived in stronger symbiosis with their owners and was most active during the photophase (daytime) compared to individuals having outdoor access more often and which exhibited more robust daily rhythmicity and the highest level of activity during the scotophase (nighttime, [23]). The results of the present study should, however, be compared with observations from similar activity tracking methodology, i.e. data from daily covered distance, contrary to studies using accelerometers technologies (such as [23]), for example.

\section{Conclusion}

A proper analysis of daily rhythms requires reliable and complex recording tools providing large and objective numbers of data. During this study, we validated a new way to analyse daily locomotor and feeding rhythms in the cat using precise $24 \mathrm{~h} / 24$ automatic recording technologies (i.e. UWB and passive RFID) and specific chronobiological parameters in a colony of cats living in an indoor environment. This population of cats showed two main peaks of activity and consumption: in the morning, especially before sunrise and renewal of food, and in the evening, following the end of the work day of the animal staff of cattery and before sunset. The cats therefore displayed bimodality in their rhythms, along 24-h periodicity, which is not affected by the sex of the cats. In order to better dissociate the influence twilights have on feline behaviour, a similar study on cats at different twilight times (e.g. according to seasons) could help clarify it. This would also enable to study the impact of day-length on the behaviour of cats. Our results open 
new avenues for developing nutritional and housing guidelines fitted to the rhythms of the cats.

\section{Supplementary information}

Supplementary information accompanies this paper at https://doi. org/10.1186/s40317-019-0188-0.

Additional file 1: Individual results of locomotor activity and feeding behaviours and rhythms of the cats.

Additional file 2: Statistical significance of one-way repeated-measures ANOVA comparing the distance covered by the cats every hour.

Additional file 3: Statistical significance of one-way repeated-measures ANOVA comparing the food consumption of the cats every hour.

\section{Acknowledgements}

The authors express their gratitude to Sandrine Vialle and Elisabeth Guy for their involvement and cooperation in this study. They also wish to thank Amanda Mercier, Sandrine Michel, Pascal Boisot and the animal technicians of Royal Canin's cattery who helped for a smooth progress of the protocols.

\section{Authors' contributions}

The idea for the paper was conceived by JS. The creation and improvement of the software were performed by JS and MP. The experiments were designed by JS and EC and were performed by SL, JS and MP. The data were collected by SL and MP and were analysed by MP. BD, JS, EC and VB helped in the interpretation of the data made by MP. The paper was written by MP and was substantively revised by JS, EC, BD and VB. All authors read and approved the final manuscript.

\section{Funding}

This study has been funded by Royal Canin.

\section{Availability of data and materials}

The data that support the findings of this study are available from Royal Canin but restrictions apply to the availability of these data, which were used under license for the current study, and so are not publicly available. Data are, however, available from the authors upon reasonable request and with permission of Royal Canin.

\section{Ethics approval and consent to participate}

This protocol was approved by Royal Canin's ethical committee.

\section{Consent for publication}

Not applicable.

\section{Competing interests}

The authors declare that they have no competing interests.

\section{Author details}

${ }^{1}$ Institut Des Neurosciences Cellulaires Et Intégratives (INCI), CNRS, Université de Strasbourg, 8 Allée Du Général Rouvillois, 67000 Strasbourg, France. ${ }^{2}$ Royal Canin Research Center, 650 Avenue de La Petite Camargue, 30470 Aimargues, France. ${ }^{3}$ Ecole Nationale Vétérinaire d'alfort (ENVA), 7 Avenue Du Général de Gaulle, 94700 Maisons-Alfort, France.

Received: 12 July 2019 Accepted: 10 December 2019

Published online: 21 December 2019

\section{References}

1. Carpenter GA. The circadian activity rhythm of mammals: a comparison of models and experiments. In: Carpenter GA, editor. Temporal order. Berlin: Springer; 1985. p. 263-72.

2. Dards JL. The population ecology of feral cats (Felis catus L.) in Portsmouth Dockyard. Ph.D. thesis, University of Bradford. 1979.
3. Golombek DA, Rosenstein RE. Physiology of circadian entrainment. Physiol Rev. 2010;90(3):1063-102. https://doi.org/10.1152/physrev.00009 2009.

4. Goszczyński J, Krauze D, Gryz J. Activity and exploration range of house cats in rural areas of central Poland. Folia Zool. 2009:58(4):363-71.

5. Haspel C, Calhoon RE. Activity patterns of free-ranging cats in Brooklyn, New York. J Mammal. 1993;74(1):1-8. https://doi.org/10.2307/1381900.

6. Hawking F, Lobban MC, Gammage K, Worms MJ. Circadian rhythms (activity, temperature, urine and microfilariae) in dog, cat, hen, duck Thamnomys and Gerbillus. Biol Rhythm Res. 1971;2(4):455-73. https://doi. org/10.1080/09291017109359289.

7. Horn JA, Mateus-Pinilla N, Warner RE, Heske EJ. Home range, habitat use, and activity patterns of free-roaming domestic cats. J Wildl Manag. 2011;75(5):1177-85. https://doi.org/10.1002/jwmg.145.

8. Houpt KA. Domestic animal behavior for veterinarians and animal scientists. Hoboken: Wiley; 2011.

9. Izawa M. Daily activities of the feral cat Felis catus Linn. J Mammal Soc Japan. 1983:9:219-28.

10. Johnson RF, Randall S, Randall W. Freerunning and entrained circadian rhythms in activity, eating and drinking in the cat. Biol Rhythm Res. 1983;14(4):315-27. https://doi.org/10.1080/09291018309359825.

11. Jones E, Coman BJ. Ecology of the feral cat Felis catus (L.), in South-eastern Australia III. Home ranges and population ecology in semiarid Northwest Victoria. Wildlife Res. 1982;9(3):409-20. https://doi.org/10.1071/ wr9820409.

12. Kanarek RB. Availability and caloric density of the diet as determinants of meal patterns in cats. Physiol Behav. 1975;15(5):611-8. https://doi. org/10.1016/s0031-9384(75)80037-0.

13. Kane E, Rogers QR, Morris JG. Feeding behavior of the cat fed laboratory and commercial diets. Nutr Res. 1981;1(5):499-507. https://doi. org/10.1016/s0271-5317(81)80053-x.

14. Kas MJ, Edgar DM. A nonphotic stimulus inverts the diurnal-nocturnal phase preference in Octodon degus. J Neurosci. 1999;19(1):328-33. https ://doi.org/10.1523/jneurosci.19-01-00328.1999.

15. Kavanau JL. Locomotion and activity phasing of some medium-sized mammals. J Mammal. 1971;52(2):386-403. https://doi.org/10.2307/13786 81.

16. Konecny MJ. Home range and activity patterns of feral house cats in the Galapagos Islands. Oikos. 1987;1:17-23.

17. Kuwabara N, Seki K, Aoki K. Circadian, sleep and brain temperature rhythms in cats under sustained daily light-dark cycles and constant darkness. Physiol Behav. 1986;38(2):283-9. https://doi.org/10.1016/00319384(86)90164-2.

18. Lewis LD, Morris ML, Hand MS. Alimentation clinique des petits animaux. 3rd ed. Topeka: Mark Morris Assoc; 1987.

19. Macdonald DW, Apps PJ. The social behaviour of a group of semidependent farm cats, Felis catus: a progress report. Carnivore Genet Newslett. 1978;3(7):256-68.

20. Mistlberger RE. Circadian regulation of sleep in mammals: role of the suprachiasmatic nucleus. Brain Res Rev. 2005;49(3):429-54. https://doi. org/10.1016/j.brainresrev.2005.01.005

21. Mugford RA, Thorne CJ. Comparative studies of meal patterns in pet and laboratory housed dogs and cats. In: Anderson RS, editor. Nutrition of the Dog and Cat. Oxford: Pergamon Press; 1980. p. 3-14.

22. Parker M, Lamoureux S, Allouche B, Brossier JA, Weber M, Feugier A, Moniot D, Deputte B, Biourge V, Serra J. Accuracy assessment of spatial organization and activity of indoor cats using a system based on UltraWide Band technology. J Vet Behav Clin Appl Res. 2017;21:13-9. https://doi.org/10.1016/j.jveb.2017.06.003.

23. Piccione G, Marafioti S, Giannetto C, Panzera M, Fazio F. Daily rhythm of total activity pattern in domestic cats (Felis silvestris catus) maintained in two different housing conditions. J Vet Behav Clin Appl Res. 2013;8(4):189-94. https://doi.org/10.1016/j.jveb.2012.09.004.

24. Podberscek AL, Blackshaw JK, Beattie AW. The behaviour of laboratory colony cats and their reactions to a familiar and unfamiliar person. Appl Anim Behav Sci. 1991;31(1):119-30. https://doi.org/10.1016/01681591(91)90159-u.

25. Randall W, Johnson RF, Randall S, Cunningham JT. Circadian rhythms in food intake and activity in domestic cats. Behav Neurosci. 1985;99(6):1162-75. https://doi.org/10.1037//0735-7044.99.6.1162. 
26. Randall W, Cunningham JT, Randall S, Luttschwager J, Johnson RF. A two-peak circadian system in body temperature and activity in the domestic cat, Felis catus L. J Therm Biol. 1987;12(1):27-37. https://doi. org/10.1016/0306-4565(87)90020-9.

27. Redlin U. Neural basis and biological function of masking by light in mammals: suppression of melatonin and locomotor activity. Chronobiol Int. 2001;18(5):737-58. https://doi.org/10.1081/cbi-100107511.

28. Refinetti R, Menaker M. The circadian rhythm of body temperature. Physiol Behav. 1992;51(3):613-37. https://doi.org/10.1016/00319384(92)90188-8.

29. Refinetti R. Comparison of the body temperature rhythms of diurnal and nocturnal rodents. J Exp Zool. 1996;275(1):67-70. https://doi.org/10.1002/ (sici)1097-010x(19960501)275:1\%3c67:aid-jez10\%3e3.0.co;2-u.

30. Refinetti R, Cornélissen G, Halberg F. Procedures for numerical analysis of circadian rhythms. Biol Rhythm Res. 2007;38(4):275-325. https://doi. org/10.1080/09291010600903692.

31. Refinetti R, Wassmer T, Basu P, Cherukalady R, Pandey VK, Singaravel M, Giannetto C, Piccione G. Variability of behavioral chronotypes of 16 mammalian species under controlled conditions. Physiol Behav. 2016;161:539. https://doi.org/10.1016/j.physbeh.2016.04.019.

32. Sharma VK. Adaptive significance of circadian clocks. Chronobiol Int. 2003;20(6):901-19. https://doi.org/10.1081/cbi-120026099.

33. Shkolnik A. Diurnal activity in a small desert rodent. Int J Biometeorol. 1971;15(2):115-20. https://doi.org/10.1007/bf01803884.
34. Sokolove PG, Bushell WN. The Chi square periodogram: its utility for analysis of circadian rhythms. J Theor Biol. 1978;72(1):131-60. https://doi. org/10.1016/0022-5193(78)90022-x.

35. van Someren EJ, Hagebeuk EE, Lijzenga C, Scheltens P, de Rooij SE, Jonker C, Pot A-M, Mirmiran M, Swaab DF. Circadian rest-activity rhythm disturbances in Alzheimer's disease. Biol Psychiatr. 1996;40(4):259-70. https:// doi.org/10.1016/0006-3223(95)00370-3.

36. van Someren EJ, Swaab DF, Colenda CC, Cohen W, McCall WV, Rosenquist PB. Bright light therapy: improved sensitivity to its effects on rest-activity rhythms in Alzheimer patients by application of nonparametric methods. Chronobiol Int. 1999;16(4):505-18. https://doi.org/10.3109/0742052990 8998724.

37. Walls GL. Adaptations to nocturnal activity. The vertebrate eye and its adaptive radiation. Oxford: Cranbrook Institute of Science; 1942. p. 206-46. https://doi.org/10.5962/bhl.title.7369.

38. Witting W, Kwa IH, Eikelenboom P, Mirmiran M, Swaab DF. Alterations in the circadian rest-activity rhythm in aging and Alzheimer's disease. Biol Psychiatr. 1990;27(6):563-72. https://doi.org/10.1016/00063223(90)90523-5.

\section{Publisher's Note}

Springer Nature remains neutral with regard to jurisdictional claims in published maps and institutional affiliations.
Ready to submit your research? Choose BMC and benefit from:

- fast, convenient online submission

- thorough peer review by experienced researchers in your field

- rapid publication on acceptance

- support for research data, including large and complex data types

- gold Open Access which fosters wider collaboration and increased citations

- maximum visibility for your research: over $100 \mathrm{M}$ website views per year

At BMC, research is always in progress.

Learn more biomedcentral.com/submissions 